\title{
Изопараметрические гетероструктуры AllnGaAsP/InP и их свойства
}

\author{
(ㄱ Д.Л. Алфимова, Л.С. Лунин , М.Л. Лунина, А.С. Пащенко, Э.М. Данилина \\ Федеральный исследовательский центр Южный научный центр Российской академии наук, \\ 344006 Ростов-на-Дону, Россия \\ ฯ E-mail: lunin_Is@mail.ru
}

Поступила в Редакцию 17 декабря 2018 г.

В окончательной редакции 25 января 2019 г.

Принята к публикации 30 января 2019 г.

Обсуждается влияние условий выращивания на структурное совершенство тонкопленочных гетероструктур AlInGaAsP/InP. Определены основные параметры, определяющие структурное совершенство и качество поверхности тонких эпитаксиальных пленок AlInGaAsP, выращенных на подложках фосфида индия из жидкой фазы в поле температурного градиента.

Ключевые слова: гетероструктуры, коэффициент термического расширения, кривая дифракционного отражения, упругие напряжения, дислокации.

DOI: 10.21883/FTP.2019.07.47865.9045

\section{1. Введение}

Многокомпонентные твердые растворы соединений $\mathrm{A}^{\mathrm{III}} \mathrm{B}^{\mathrm{V}}$ могут служить основой гетероструктур для эффективных оптоэлектронных приборов [1-14]. Необходимым условием этого является получение совершенных по структуре эпитаксиальных слоев твердых растворов соединений $\mathrm{A}^{\mathrm{III}} \mathrm{B}^{\mathrm{V}}$ и совмещение их по периоду решетки с бинарными соединениями, обладающими требуемыми электрофизическими характеристиками. С помощью тройных и четверных твердых растворов типа $\mathrm{A}^{\mathrm{III}} \mathrm{B}^{\mathrm{V}}$ успешно решается задача создания приборов оптоэлектроники в широком спектральном диапазоне. Однако в целом проблема дальнейшего расширения спектрального диапазона и повышения структурного совершенства гетероструктур за счет согласования эпитаксиальных слоев по периоду решетки и коэффициенту термического расширения (КТР) остается актуальной. Простейший путь решения этой проблемы - переход к пятикомпонентным изопараметрическим гетероструктурам соединений $\mathrm{A}^{\mathrm{III}} \mathrm{B}^{\mathrm{V}}$.

Цель настоящей работы заключается в исследовании структурного совершенства тонкопленочных изопараметрических гетероструктур AlInGaAsP/InP в зависимости от условий выращивания.

\section{2. Экспериментальная часть}

Выращивание тонких эпитаксиальных пленок AlInGaAsP на подложках фосфида индия осуществлялось методом зонной перекристаллизации в поле температурного градиента (ЗПГТ) [15]. В качестве подложечного материала использовались монокристаллические пластины фосфида индия с ориентацией по плоскостям (100) и (111) типа: фосфид индия электронного типа проводимости (ФИЭ), фосфид индия электронного типа, легированный осовом (ФИЭО) и фосфид индия электронного шипа легированный теллуром (ФИЭТ) с концентрацией $5 \cdot 10^{6} \leq n \leq 5 \cdot 10^{8} \mathrm{~cm}^{-3}$. Пластины, предварительно отшлифованные и полированные до 14-20 класса чистоты, подвергались химическому травлению $\mathrm{HCl}: \mathrm{HNO}_{3}: \mathrm{H}_{2} \mathrm{O}$ при температуре $343 \mathrm{~K}$ в течение $90 \mathrm{c}$.

Толщина подложек после обработки составила 350-400 мкм. Далее пластины InP промывали в дистиллированной воде и обрабатывали в парах толуола для удаления остатков органических веществ.

В качестве жидкой зоны использовали растворрасплав чистых In, Al, Ga, P, As толщиной 10-200 мкм. В качестве перекристаллизуемого источника использовались пластины InP для варизонных гетероструктур, или поликристалл InAlPAs для гетероструктур постоянного состава. Методика получения таких композиций описана нами ранее [16,17]. Полученные „сандвичи“ $[(\mathrm{InP})-($ жидкая зона In-Al-Ga-P-As) - (InP или поликристалл InAlPAs)] подвергали перекристаллизации в поле температурного градиента. Печь позволяла изменять температуру от комнатной до $1223 \mathrm{~K}$ и градиент температуры в пределах $10 \leq G \leq 100 \mathrm{~K} /$ см. Камеру вначале откачивали до $10^{-3} \mathrm{~Pa}$, а затем наполняли водородом до $0.5 \mathrm{~Pa}$. Процесс в ЗПГТ проводили в потоке водорода.

Структурное совершенство тонкопленочных гетероструктур AlInGaAsP/InP и определение параметров решеток проводили с использованием рентгеновской дифракции. Съемка кривых дифракционного отражения (КДО) рентгеновского излучения проводилась на высокоразрешающем рентгеновском дифрактометре TPC-1 в двухкристальной геометрии с использованием $\mathrm{Cu} K_{\alpha_{1,2}}$-излучения. Учитывалась также форма дифракционных кривых и наличие или отсутствие интерференционных максимумов, несущих информацию о качестве поверхности эпитаксиального слоя и планарности границы раздела пластина/подложка.

Изучение морфологии поверхности и состава пленок AlInGaAsP проводили на атомно-силовом микроскопе $(\mathrm{ACM})$ (atomic-force microscope $(\mathrm{AFM})$ ) Solver HV 
и сканирующем растровом электронном микроскопе Quanta-200 в ЦКП „Нанотехнологии“ ЮРГПУ (НПИ). Методом масс-спектроскопии вторичных нейтральных частиц [18] были получены концентрационные профили эпитаксиальных пленок AlInGaAsP, выращенных на подложках InP. Масc-спектры получали при травлении поверхности гетероструктур ионами аргона с энергией 4 кэВ и плотностью тока 50 мкА/см². Вторичные частицы регистрировали квадрупольным масс-спектрометром Micromass PC100 в режиме многоканального ионного мониторинга, отображающего динамику измерения 16 выбранных элементов или соединений. В этом режиме имеется возможность исключения фона, что облегчает анализ элементов, образующихся в вакуумной камере при давлении аргона $6.5 \cdot 10^{-4} \mathrm{~Pa}$.

Измерения фотолюминесценции проводили в спектральном диапазоне от 950 до $1500 \mathrm{~nm}$ при температуре $300 \mathrm{~K}$ и в жидком азоте при $77 \mathrm{~K}$ в криостате с кварцевыми окнами. В качестве источника возбуждающего оптического излучения использовался инжекционный лазер с длиной волны 402 нм и мощностью излучения 8.5 мВт, фотодетектором служил германиевый фотодиод (ФПУ ФДГ) с рабочим спектральным диапазоном длин волн от 0.5 до 2 мкм. Возбуждение фотолюминесценции осушествлялось со стороны эпитаксиальных слоев.

\section{3. Экспериментальные результаты и их обсуждение}

Результаты оже-анализа по толщине тонких пленок AlInGaAsP, полученных при перекристаллизации InP, показали, что на поверхности присутствуют все компоненты (рис. 1). После мягкой очистки интенсивности этих пиков возросли. До глубины 500 нм интенсивность пиков In и $\mathrm{P}$ не изменялась, так как идет подпитка из источника InP по этим компонентам, в то же время наблюдается достаточно быстрое

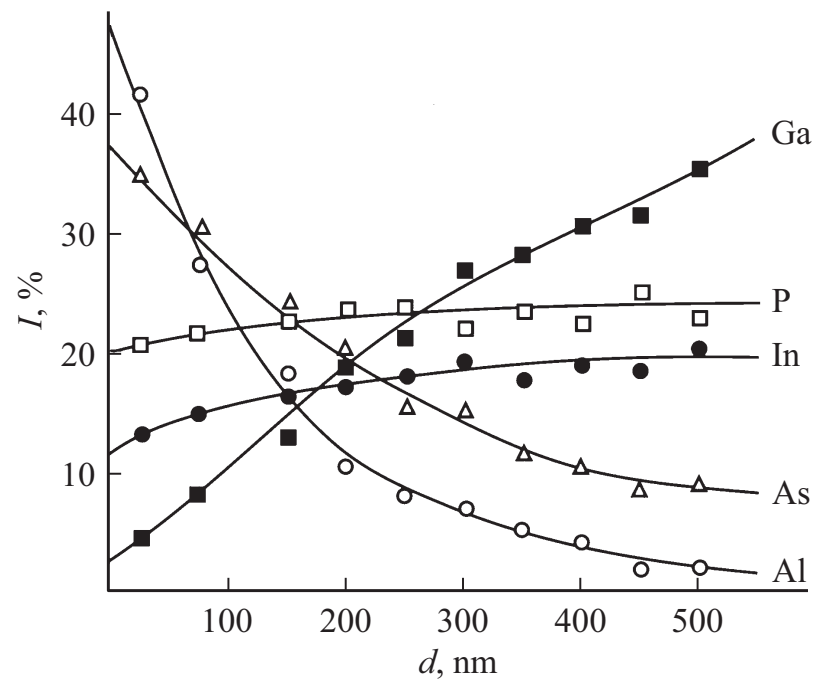

Рис. 1. Профили распределения элементов по глубине гетеростуктуры $\mathrm{AlGaInAsP} / \mathrm{InP}$.

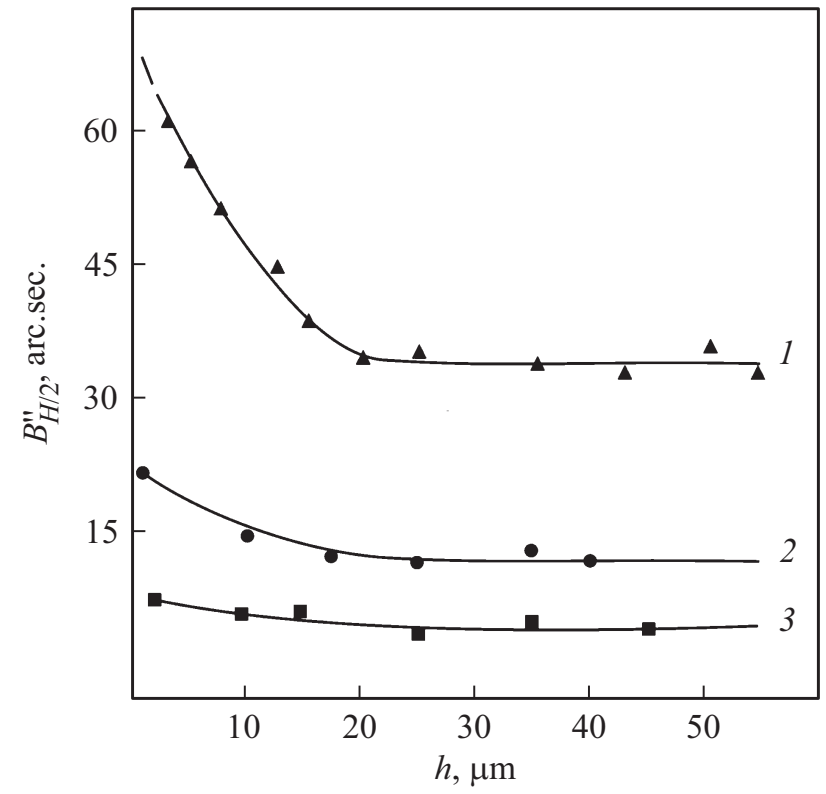

Рис. 2. Распределение ширины КДО на половине высоты по толщине эпитаксиальных слоев твердых растворов $\mathrm{Al}_{y} \mathrm{Ga}_{x} \mathrm{In}_{x-y} \mathrm{As}_{z} \mathrm{P}_{1-z}$, выращенных на подложках InP при $T=913 \mathrm{~K}, l=80$ мкм, $G=30 \mathrm{~K} / \mathrm{cм}: l-x=0, y=0.28$, $z=1.0 ; 2-x=0, y=0.28, z=0.6 ; 3-x=0.08, y=0.28$, $z=0.6$.

возрастание галлия. Концентрация мышьяка и алюминия в объеме гетероструктуры убывает и на глубине более $700 \mathrm{Hм}$ находится ниже предела чувствительности метода. Такое поведение $\mathrm{Al}$ и As связано с большими коэффициентами распределения этих компонентов, вследствие чего они быстро расходуются из раствора-расплава [19]. При использовании перекристаллизуемого источника-поликристалла (InAlPAs) в оже-спектрах гетероструктур AlInGaAsP/InP интенсивность всех компонентов практически не изменялась, что говорит об однородности по составу компонентов эпитаксиальных пленок. Отметим также отсутствие пиков, относящихся к кислороду и углероду, что говорит об отсутствии оксидных и карбидных соединений элементов в объеме гетероструктур.

Исследования структурного совершенства показали, что дефектность пленок многокомпонентных твердых растворов уменьшалась по мере увеличения числа компонентов. Трехкомпонентные твердые растворы $\mathrm{Ga}_{x} \mathrm{In}_{1-x} \mathrm{As}$ на InP имеют один состав, изопериодический с InP (при $x=0.47, \Delta a / a \approx 10^{4}$ при $T=293 \mathrm{~K}$ ). Измерения, проведенные на косых шлифах однородных пленок $\mathrm{Ga}_{0.47} \mathrm{In}_{0.53} \mathrm{As}$, показали, что ширина линий качания (на половине высоты $B_{H / 2}$ ) одинакова во всех точках слоя, кроме участков вблизи гетерограницы (рис. 2). Гетеропереход вызывает заметное уширение кривых качания до 47" для $\mathrm{Ga}_{0.47} \mathrm{In}_{0.53} \mathrm{As} / \mathrm{InP}$, постепенно уменьшаясь по мере удаления от гетерограницы и на расстоянии более 500 нм достигает $B_{H / 2} \approx 30^{\prime \prime}$. 

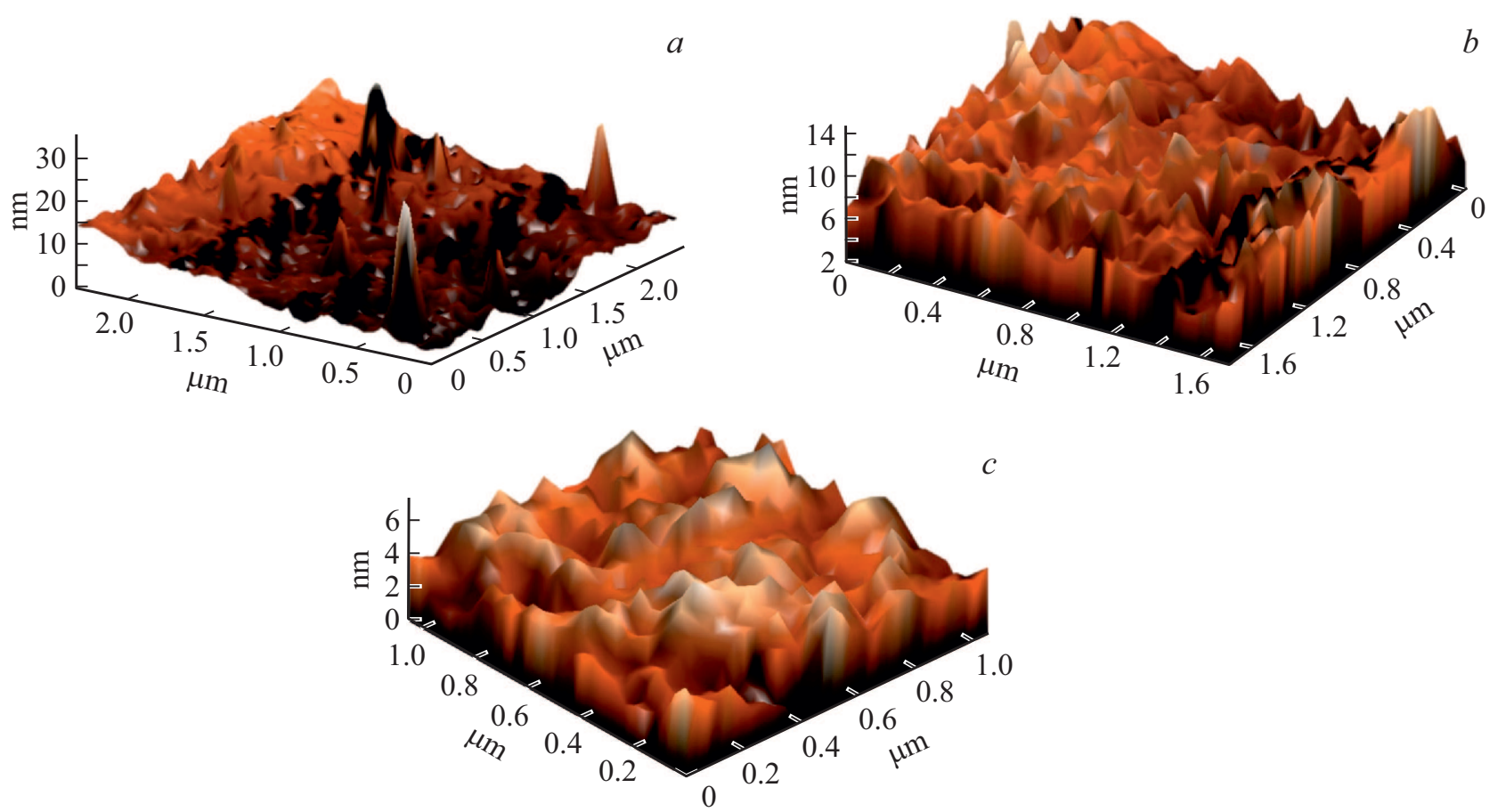

Рис. 3. Морфология поверхности эпитаксиальных слоев твердых растворов: $a$ - GaInAs/InP, $b-\mathrm{GaInAsP} / \mathrm{InP}, c-$ AlGaInAsP/InP.

При исследовании части эпитаксиальной пленки $\mathrm{Ga}_{0.47} \mathrm{In}_{0.53} \mathrm{As}$ за пределами приграничной области установлено, что по мере увеличения концентрации GaAs в источнике от $x_{1}=0.47$ до $x_{1}=0.84 B_{H / 2}$ увеличивается от 30 до $60^{\prime \prime}$.

Для увеличения количества составов, изопериодных c InP, и для полного согласования периода кристаллической решетки пленки с подложкой, а следовательно, снижения дефектности, в твердый раствор вводится четвертый компонент - фосфор. Морфология поверхности и качество гетероструктур на основе InP весьма чувствительны к величине рассогласования периода решетки и КТР. На рис. 2 представлены результаты исследования КДО по толщине различных гетероструктур

$$
\begin{gathered}
\mathrm{Ga}_{0.47} \mathrm{In}_{0.53} \mathrm{As} / \mathrm{InP}, \\
\mathrm{Ga}_{x} \mathrm{In}_{1-x} \mathrm{As}_{y} \mathrm{P}_{1-y} / \mathrm{InP}, \\
\mathrm{Al}_{x} \mathrm{Ga}_{y} \mathrm{In}_{1-x-y} \mathrm{As}_{z} \mathrm{P}_{1-z} / \mathrm{InP} .
\end{gathered}
$$

Видно, что $B_{H / 2}$ одинакова во всех точках однородных по составу многокомпонентных пленок, кроме участков вблизи гетерограницы. Сравнение кривых 1 и 2 на рис. 2 показало, что введение фосфора в GaInAs уменьшает дефектность гетерограницы за счет увеличения решеточного согласования пленки и подложки. Однако дефектность гетерограницы даже для изопериодных составов твердых растворов GaInAsP сохраняется довольно значительной из-за различия КТР спрягающихся слоя и подложки. При введении пятого компонента $\mathrm{Al}$ в GaInAsP дефектность гетерограницы значительно уменьшается (рис. 2, кривая 3). Исследование морфологии поверхности для эпитаксиальных пленок GaInAs/InP (рис. 3, $a$ ), GaInAsP/InP (рис. 3,b) и AlGaInAsP/InP (рис. $3, c$ ) показало уменьшение параметров шероховатости от 60 до 6 нм при переходе от трехкомпонентных гетероструктур к пятикомпонентным.

$\mathrm{Ha}$ рис. 4 (кривые 1,2) показано влияние состава на структурное совершенство гетероструктур AlGaInAsP/InP. На структурное совершенство тонкопленочных гетероструктур AlGaInAsP/InP в процессе ЗПГТ оказывают влияние толщина зоны $(l)$, температура $(T)$ и ее градиент $(G)$. На рис. 4 приведены зависимости $B_{H / 2}$ $(l, T$ и $G)$. Зависимости $B_{H / 2}$ от толщины зоны (рис. 4 , кривая 3) показали, что для тонких зон $(l<60$ мкм) наблюдается значительное ухудшение качества эпитаксиальных пленок AlGaInAsP, особенно это проявляется для нанослоев $(l<30$ мкм). Это связано с тем, что в тонких зонах не происходит полного растворения микрочастиц при перекристаллизации источника, в результате в эпитаксиальных пленках наблюдаются нановключения, нарушаются планарность гетерограницы и однородность состава. Для $l>60$ мкм по мере увеличения толщины зоны улучшается качество пленок, выражаемое в уменьшении $B_{H / 2}$. Однако дальнейшее увеличение толщины зоны $l>200$ мкм приводит к увеличению градиента температуры, вследствие чего нарушается стабильность фронта кристаллизации и возникают отклонения от стехиометрического состава из-за несоответствия скоростей кристаллизации и растворения на границах жидкой зоны [20]. Этим и объясняется ухудшение качества гетероструктур AlGaInAsP/InP, выраженное в уширении $B_{H / 2}$, которое достигает $>80^{\prime \prime}$ при $l \geq 200$ мкм. 
Результаты измерений полуширины $B_{H / 2}$ КДО для изопараметрических гетероструктур AlGaInAsP/InP, выращенных при различных температурах и градиентах температуры, показали (рис. 4, кривые 4 и 5), что совершенство гетероструктур ухудшается при их увеличении и достигает значительных величин: $\geq 60^{\prime \prime}$. Это обусловлено нарушением теплового и диффузионного равновесия, вследствие чего нарушается стабильность фронта кристаллизации и появляются микровключения на гетерогранице гетероструктуры AlGaInAsP/InP.

Спектры фотолюминесценции однородных по составу гетероструктур GaInAs/InP (1), GaInAsP/InP (2) и AlGaInAsP/InP (3), полученные при $300 \mathrm{~K}$, приведены на рис. 4, где показано, что спектры ФЛ имеют одинокий пик. Люминесценция при $300 \mathrm{~K}$ в основном обусловлена испусканием, связанным с краем зоны. Исследования показали, что добавление компонентов P в GaInAs и Al в GaInAsP приводит к увеличению интенсивности и уменьшению ширины полосы излучения на половине высоты пиков. Интенсивность и ширина полосы излучения определяются в основном кристаллическим совершенством пленок.

В случае трехкомпонентных пленок дефектность гетероструктуры GaInAs/InP определяется химическим составом или величиной ширины запрещенной зоны

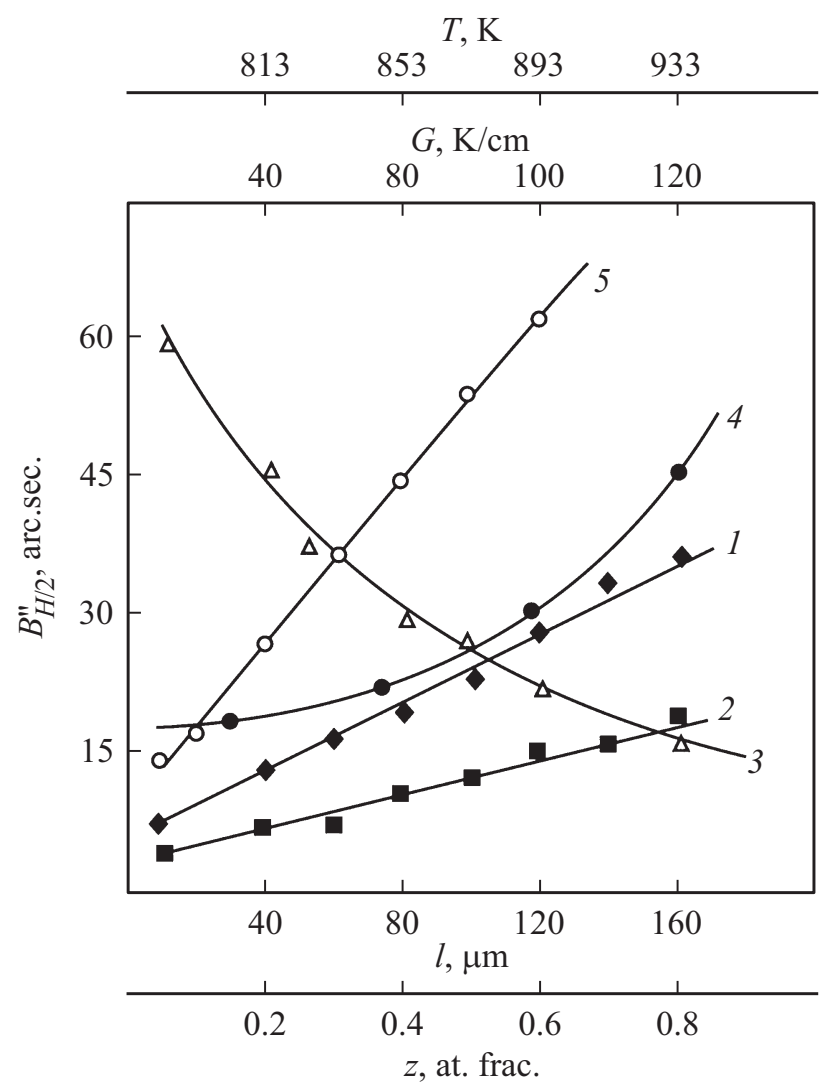

Рис. 4. Зависимости $B_{H / 2}$ от $z$ (кривые $1-$ GaInAsP и 2 - AlGaInAsP), толщины жидкой зоны $l$ (кривая 3), температуры $T$ (кривая 4) и ее градиента $G$ (кривая 5 ) для гетероструктур $\mathrm{Al}_{x} \mathrm{Ga}_{y} \mathrm{In}_{1-x-y} \mathrm{As}_{z} \mathrm{P}_{1-z} / \mathrm{InP}$.

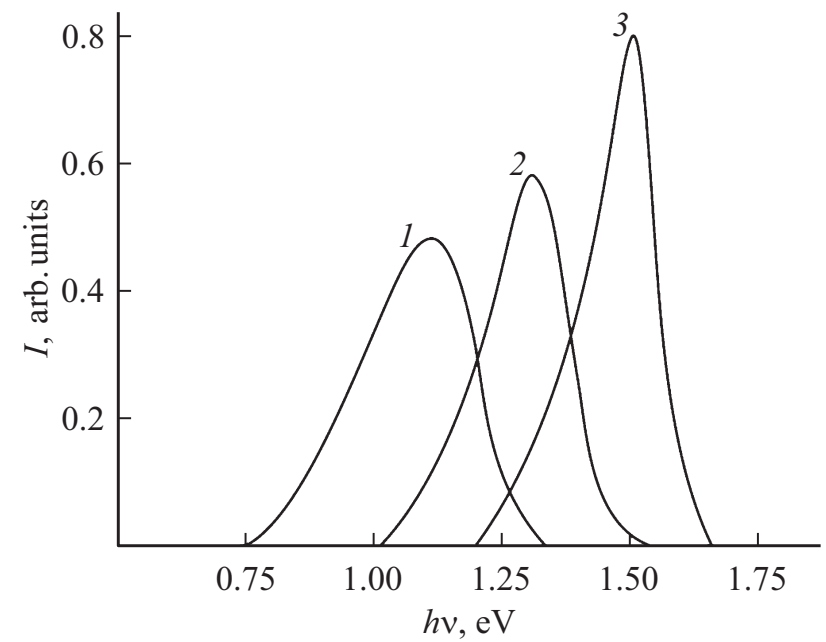

Рис. 5. Спектры фотолюминесценции эпитаксиальных слоев: 1 - GaInAsP/InP, 2 - GaInAsP/InP, 3 - AlGaInAsP/InP.

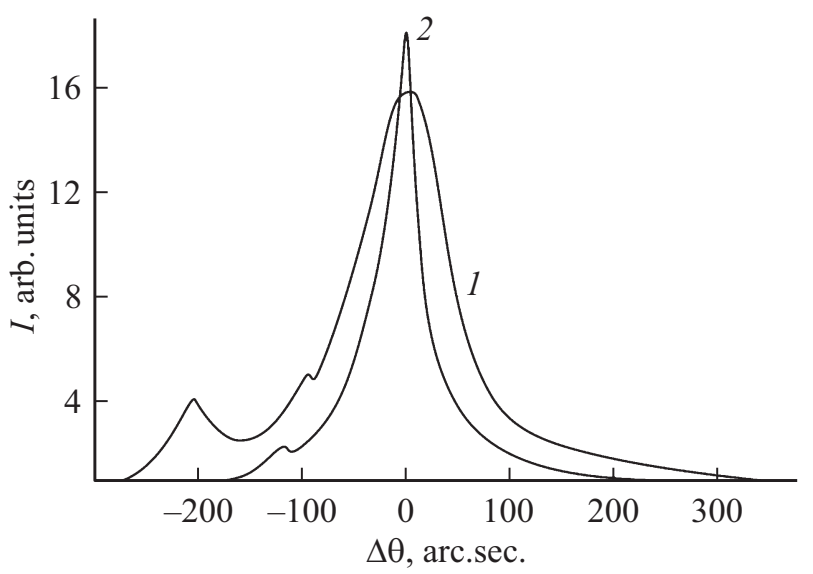

Рис. 6. Кривая дифракционного отражения от эпитаксиального слоя: 1 - GaInAsP/InP, 2 - AlGaInAsP/InP.

$E_{g}$, поскольку чем сильнее состав слоя отличается от состава подложки, тем больше разность параметров решетки на гетерогранице. В четверных гетероструктуpax GaInAsP/InP наличие дополнительной химической степени свободы позволяет согласовывать параметры решетки на гетерогранице. Ширина спектральной полосы ФЛ определяется прежде всего рассогласованием параметров решеток, при этом чем больше разность $E_{g}$ пленки и подложки, тем сильнее такое рассогласование и шире полоса излучения. В пятикомпонентных гетероструктурах устраняется также рассогласование по КТР, что приводит к улучшению кристаллического совершенства и люминесцентных свойств (рис. 5, кривые 2 и 3, рис. 6).

\section{4. Заключение}

Структурное совершенство тонкопленочных изопараметрических гетероструктур AlGaInAsP/InP зависит от 
состава, толщины жидкой зоны, температуры и его градиента. Комплексный анализ качества поверхности и структурного совершенства тонкопленочных гетероструктур AlGaInAsP/InP выявил оптимальные параметры процесса ЗПГТ, при которых эпитаксиальные пленки имели минимальную шероховатость, $\approx 6 \mathrm{Hм}$, и высокое кристаллическое совершенство $B_{H / 2}<20^{\prime \prime}$, $773 \leq T \leq 813 \mathrm{~K}, 10 \leq G \leq 20 \mathrm{~K} / \mathrm{cм}, 60 \leq l \leq 80$ мкм.

Полуширина КДО и полос спектров ФЛ для гетероструктур AlGaInAsP/InP меньше, чем в случае GaInAs/InP и GaInAsP/InP, что говорит о более высоком совершенстве пятикомпонентных гетероструктур и поэтому данные структуры предпочтительнее для высокоэффективных приборов, основанных на излучательной рекомбинации.

\section{Финансирование работы}

Работа выполнена в рамках государственного задания Южного научного центра Российской академии наук на 2019 год (№ государственной регистрации проекта 01201354240), а также при финансовой поддержке Российского фонда фундаментальных исследований в рамках научного проекта № 17-08-01206 А.

\section{Конфликт интересов}

Авторы заявляют, что у них нет конфликта интересов.

\section{Список литературы}

[1] P.V. Seredin, A.V. Glotov, A.S. Lenshin, I.N. Arsentyev, D.A. Vinokurov. Semiconductors, 48, 21 (2014).

[2] H.Z. Song, M. Hadi, Y. Zheng, B. Shen, L. Zhang, Z. Ren, R. Gao, Z.M. Wang. Nanoscale Res. Lett., 12, 128 (2017).

[3] S.E. Gulebaglan, E.K. Dogan, M. Aycibin, M.N. Secuk, B. Erdinc, H. Akkus. Cent. Eur. J. Phys., 11, 1680 (2013).

[4] A.G. Gladyshev, I.I. Novikov, L.Ya. Karachinsky, D.V. Denisov, S.A. Blokhin, A.A. Blokhin, A.M. Nadtochiy, A.S. Kurochkin, A.Yu. Egorov. Semiconductors, 50, 1186 (2016).

[5] D.A. Vinokurov, V.A. Kapitonov, A.V. Lyutetskiy, D.N. Nikolaev, N.A. Pikhtin, S.O. Slipchenko, A.L. Stankevich, V.V. Shamakhov, L.S. Vavilova, I.S. Tarasov. Semiconductors, 46, 1321 (2012).

[6] V.V. Shamakhov, D.N. Nikolaev, A.V. Lyutetskiy, K.V. Bakhvalov, M.G. Rastegaeva, S.O. Slipchenko, N.A. Pikhtin, I.S. Tarasov. Semiconductors, 48, 373 (2014).

[7] F. Schattiger, D. Bauer, J. Demsar, T. Dekorsy, J. Kleinbauer, D.H. Sutter, J. Puustinen, M. Guina. Appl. Phys. B, 106, 605 (2012).

[8] V.D. Rumyantsev, A.V. Chekalin, D.A. Malevskiy, A.N. Panchak, N.A. Sadchikov, V.M. Andreev, N.Y. Davidyuk, A.L. Luque. IEEE J. Photovolt., 5, 1715 (2015).

[9] A. Luque, I. Ramiro, P. Garcia-Linares, E. Antolin, A. Marti, A. Panchak, A. Vlasov, V. Andreev, A. Mellor. IEEE J. Photovolt., 5, 1074 (2015).

[10] M.A. Mintairov, N.A. Kalyuzhnyy, V.V. Evstropov, V.M. Lantratov, S.A. Mintairov, M.Z. Shyarts, V.M. Andreev, A. Luque. IEEE J. Photovolt., 5, 1229 (2015).
[11] R.V. Levin, A.E. Marichev, M.Z. Shvarts, E.P. Marukhina, V.P. Khyostikov, B.V. Pushnyi, V.M. Andreev, M.N. Mizerov. Semiconductors, 49, 700 (2015).

[12] M.A. Mintairov, V.V. Evstropov, S.A. Mintairov, M.Z. Shvarts, N.Kh. Timoshina, N.A. Kalyuzhnyy. Semiconductors, 49, 668 (2015).

[13] V. Khvostikov, N. Kalyuzhnyy, S. Mintairov, N. Potapovich, M. Shvarts, S. Sorokina, A. Luque, V. Andreev. AIP Conf. Proc., 1616, 21 (2014).

[14] N.A. Kalyuzhnyy, V.V. Evstropov, V.M. Lantratov, S.A. Mintairov, M.A. Mintairov, A.S. Gudovskikh, A. Luque, V.M. Andreev. Int. J. Photoenergy, 2014, 836284 (2014).

[15] В.Н. Лозовский, Л.С. Лунин, Т.А. Аскарян. Изв. вузов. Физика, 7, 41 (1989).

[16] D.L. Alfimova, L.S. Lunin, M.L. Lunina. Inorg. Mater., 50, 113 (2014).

[17] V.V. Kuznetsov, E.R. Rubtsov, E.A. Kognovitskaya, M.L. Lunina. Rus. J. Phys. Chem. A, 85, 2062 (2011).

[18] A.V. Blagin, D.P. Valyukhov, L.S. Lunin. Inorg. Mater., 44, 793 (2008).

[19] D.L. Alfimova, L.S. Lunin, M.L. Lunina, A.S. Pashchenko, S.N. Chebotarev, A.E. Kazakova. Inorg. Mater., 53, 1217 (2017).

[20] D.L. Alfimova, L.S. Lunin, M.L. Lunin, S.N. Chebotarev, D.A. Arustamyan, A.E. Kazakova. Semiconductors, 51, 1377 (2017).

Редактор Г.А. Оганесян

\section{Properties of isoparametric AllnGaAsP/InP heterostructures}

\section{D.L. Alfimova, L.S. Lunin, M.L. Lunina,} A.S. Pashchenko, E.M. Danilina

\section{Federal Research Center Southern Scientific Center Russian Academy of Sciences, 344006 Rostov-on-Don, Russia}

Abstract The paper discusses the influence of growth conditions on the structural perfection of AlInGaAsP/InP thin-film heterostructures. The main parameters determining the structural perfection and surface quality of thin AlInGaAsP epitaxial films grown on indium phosphide substrates from the liquid phase in the temperature gradiend field are determined. 